\title{
Rosângela Digiovani (Zanza), uma pioneira nos estudos antropológicos sobre aborto
}

Peter Fry

(UFRJ)
Todos nós, amigos e colegas de Rosângela Digiovani (Zanza), lamentamos a sua passagem. Além de abordar suas qualidades de professora dedicada e amiga solidária, escolho falar nesta singela homenagem sobre sua primeira pesquisa, que resultou na sua dissertação de mestrado - Projetos de vida: um estudo das representações femininas do aborto (Digiovani 1983) -, que tive o prazer de orientar junto com Mariza Corrêa.

Lá pelos idos dos últimos anos da ditadura militar, nós antropólogos na UNICAMP realizamos uma série de estudos sobre sexualidade e gênero: Verena Stolcke sobre mulheres trabalhadoras das fazendas de café na região de Campinas (Stolcke 1986); Mariza Corrêa sobre violência doméstica extrema (Corrêa 1975, 1981, 1983); e eu mesmo sobre as diversas feições da homossexualidade no Brasil. Não chega a ser surpreendente, portanto, que alguns dos nossos alunos tenham escolhido pesquisar temas relacionados. Entre eles penso em Regina Mazzariol sobre a zona de prostituição de Campinas (Mazzariol 1977), Ercy Guimarães sobre mulheres casadas de classe média do interior paulista (Guimarães 1978), Rosemary Lobert sobre os Dzi Croquettes (Lobert 1979, 2010), e Néstor Perlongher sobre os michês de São Paulo (Perlongher 1986, 1987).

Se esses temas eram todos complexos e, na época, polêmicos e inéditos, o tema escolhido pela Zanza era com certeza o mais ousado. Afinal, a questão do aborto tinha sido levantada pelo movimento feminista no Brasil apenas em 1980, e havia tanta resistência da Igreja Católica que as ativistas frearam um pouco as suas demandas pela descriminalização. As poucas pesquisas acadêmicas existentes eram predominantemente da área médica. Estas apresentavam dados assustadores sobre as altas taxas de abortos clandestinos, com as consequentes internações hospitalares e frequentes mortes, sobretudo entre as mulheres mais pobres. Mas, sendo estudos baseados em questionários com grande número de casos, não podiam entrar na intimidade das mulheres que experimentaram o processo. Achávamos que o debate ficaria muito mais rico se pudéssemos 
entender o tema através do ponto de vista de algumas mulheres que passaram pelo aborto. Zanza, então, na boa tradição da antropologia social, foi em busca de mulheres que concordariam em contar as suas experiências.

Se foi pela simpatia da Zanza e/ou pela vontade que muitas pessoas parecem ter de contar as suas experiências para relativos estranhos (Zanza observou que sentiu sensações de alívio por parte das mulheres que contaram suas histórias), não vem ao caso. Mas com cara e coragem, e com umas indicando outras, ela conseguiu identificar e conversar com dez solteiras, nove casadas e cinco desquitadas (ainda não havia divórcio no Brasil na época). Como as pesquisas anteriores haviam notado significativas diferenças entre mulheres de classes distintas (as mais pobres provocando os seus próprios abortos e/ou sofrendo a intervenção e consequências nefastas de pessoas sem nenhuma formação médica), Zanza contrapôs dezessete mulheres das "classes médias" a sete mulheres das "classes baixas". Relendo essa dissertação mais de trinta anos depois da sua defesa, fiquei pasmo ao verificar o quanto exigíamos das nossas pobres alunas, naquela época sem as bolsas de que os alunos podem usufruir hoje em dia. Fica mais que patente o imenso trabalho de campo, bem como o esforço em achar uma forma adequada de apresentar os dados.

Zanza enfrentou um problema que assola todos os que baseiam as suas pesquisas em entrevistas aprofundadas, tendo muitas vezes de escolher entre manter as entrevistas na sua inteireza ou recortá-las em temas específicos. O caminho que ela escolheu foi fazer as duas coisas, mantendo os depoimentos de três entrevistadas na sua totalidade (uma mulher solteira, uma casada e outra desquitada - assim cobrindo as três fases mais comuns dos projetos familiares de tantas mulheres) e acrescentando comentários das outras para iluminar assuntos específicos. Assim, por exemplo, ela cortava as narrativas para discutir questões como: o uso dos anticoncepcionais; as justificativas do aborto; relações com os parceiros e outros membros da família; a tomada de decisão; e a concretização do aborto em si. Mas, como era de se esperar, ao falar do aborto, as mulheres revelaram toda gama de informações sobre sexualidade, família, amor e seus projetos profissionais. A dissertação, então, vai muito além do aborto em si, sendo um retrato muito detalhado da moral sexual e familiar da época em que foi escrita, revelando muito sobre os sentidos muitas vezes implícitos subjacentes à vida social.

Pensei em resumir os principais achados da pesquisa da Zanza, mas achei melhor deixar que ela mesma fale, reproduzindo aqui ipsis litteris as últimas palavras da sua dissertação, "Retomando algumas Questões":

A experiência do aborto percebida como um "drama" nos termos propostos por Turner (1975), tendo em vista que as mulheres entrevistadas definiram o aborto como momento de intenso conflito cuja prática representa a quebra de normas jurídicas e sociais, revelou-se um momento privilegiado para se observar aspectos relativos à reprodução humana, comumente implícitos na vida cotidiana.

Nesse sentido verificou-se que os relatos não apontaram para os argumentos de ordem religiosa que condenam a prática do aborto por entender que o ser humano é portador de vida e alma a partir da concepção. A não referência à posição tradicionalmente defendida pela Igreja Católica não significa evidentemente o seu desconhecimento mas parece indicar que as justificativas das mulheres ao se decidirem pelo aborto sobrepõem-se a essas noções. Da mesma forma não foi mencionada a definição dada pela legislação penal brasileira que considera o aborto como sendo "crime contra a vida" estabelecendo penalidades no caso de sua prática. A não referência à proibição legal sugere novamente que as razões das mulheres que abortam sobrepõem-se também à definição legal. Não aparece tampouco referência ao debate pela legalização do aborto, já lançado nacionalmente por ocasião da pesquisa, 
sugerindo ser esta uma questão ainda restrita aos grupos feministas.

Nos relatos apresentados como justificativas do aborto alguns aspectos relativos à reprodução da vida humana se evidenciam e podem ser destacados a partir de sua recorrência.

A maternidade não é posta em questão. Todas desejam, ou desejaram, ter filhos e para isso estabelecem regras e formulam projetos específicos. É em relação ao projeto elaborado que se define uma gravidez como indesejável e o aborto como necessidade. Nesse sentido percebe-se claramente a existência de um projeto de vida sendo explicitado no momento em que se decide pelo aborto.

Segundo Gilberto Velho, é importante "frisar o caráter consciente do processo de projetar, que vai diferenciá-lo de outros processos determinantes ou condicionares de ação que não sejam conscientes" (1981: 27). Se a prática do aborto revela a existência de um projeto de vida sendo tomado como referência, e se os projetos são conscientes, é igualmente consciente a ação praticada no sentido de atualização e reafirmação deste projeto. O que não significa, entretanto, que os projetos sejam estáticos, ao contrário, estão sendo constantemente reformulados, uma vez que “os projetos mudam, um pode ser substituído por outro, podem se transformar. O 'mundo' dos projetos é essencialmente dinâmico na medida em que os atores têm uma biografia, isto é, vivem no tempo e na sociedade, ou seja, sujeitos à ação de outros atores e às mudanças sócio-históricas" (Velho 1981: 27).

$\mathrm{Na}$ medida em que os dados para efeito de análise foram organizados em torno de três categorias - solteiras, casadas e desquitadas - sendo que cada categoria incluía uma divisão relacionada à origem social, os projetos de vida explicitados apresentam especificidades uma vez que "os projetos são elaborados e construídos em função de experiências socioculturais, de um código, de vivências e interações interpretadas" (Velho 1981: 26).

$\mathrm{Na}$ análise das justificativas dadas ao aborto pelas mulheres solteiras pertencentes à "classe média" os projetos de vida explicitados enfatizam o investimento na carreira profissional como sendo uma etapa a ser atingida antes da maternidade, já que estabilidade profissional é apontada como condição essencial para que a maternidade se realize. A esta condição soma-se a necessidade de uma relação afetiva estável, fundamental para todas, quando se trata de ter filhos. A ênfase na carreira profissional sugere que o projeto familiar se encontra, nesse sentido, subordinado a um projeto mais amplo. Dado que ainda não ingressaram no ciclo de vida conjugal essas mulheres parecem ter à sua disposição um leque maior de alternativas para construírem suas biografias, podendo contrapor a maternidade à carreira profissional.

No caso das mulheres solteiras tomadas como contraponto para relativizar as informações obtidas com a maioria das entrevistadas, os projetos de vida explicitados nas justificativas do aborto, além de enfatizar dificuldades de ordem financeira, apresentam uma maneira diferenciada no que se refere à relação entre maternidade e trabalho. Enquanto os projetos de vida citados anteriormente apresentavam uma certa linearidade ao enfatizar a carreira profissional como prioritária em relação à maternidade, os projetos de vida explicitados nesse caso mostram que trabalho e maternidade são conciliados e as dificuldades decorrentes são atribuídas à própria condição econômica, onde um filho, inclusive, 'pode ajudar'. Apesar dessa maneira diferenciada de pensar e viver a maternidade e o trabalho, elas se assemelham a outras entrevistadas ao recolocar o projeto familiar, enfatizando a necessidade do pai e companheiro quando se referem às condições consideradas necessárias para a reprodução.

No caso das mulheres casadas, o projeto familiar já está sendo concretizado e as justificativas dadas para o aborto estão diretamente relacionadas com o casamento e mais precisamente com o desempenho do parceiro enquanto marido e pai. Nesse sentido a prática do aborto pode ter o significado de adequação do projeto familiar elaborado à realidade vivida. Isso mostra que os projetos estão sendo constantemente atualizados e reformulados no que se refere à sua adequação ao que possa ser considerado como entrave à sua realização.

As histórias de vida das mulheres casadas tomadas como contraponto não apresentam diferenças marcantes se remetidas às mulheres casadas entrevistadas anteriormente. As justificativas do aborto também estão relacionadas com o casamento e com o desempenho do parceiro como marido e pai e a prática do aborto também parece se constituir na adequação do projeto familiar à realidade vivida. 
As mulheres desquitadas pertencentes à classe média, por serem muito jovens, por terem permanecido pouco tempo casadas e por não terem tido filhos, se assemelham mais às mulheres solteiras que às casadas. Os projetos de vida novamente enfatizam o investimento na carreira profissional como prioritário em termos de condição para se ter filhos, sendo a maternidade vista como fator de impedimento no sentido de avançar profissionalmente. Por terem saído do ciclo de vida conjugal, o projeto familiar aparece, como no caso das solteiras, subordinado a um projeto mais amplo.

As experiências relatadas pelas mulheres desquitadas tomadas como contraponto, apesar de conterem diferenças, tanto em termos de idade quanto em termos de duração da vida conjugal e ainda pelo fato de que tiveram filhos, apresentam semelhanças em relação ás desquitadas citadas anteriormente na medida em que, por terem saído do ciclo de vida conjugal, sobrepõem o projeto de vida ao projeto familiar, considerado como realizado.

A análise da situação das mulheres desquitadas nos permite assim ter um quadro completo da trajetória percorrida pelas mulheres nas várias fases de um projeto familiar. Nesse sentido o projeto familiar varia de acordo com a posição ocupada pela mulher dentro de um continuum que poderíamos chamar de ciclo de vida conjugal-solteiras, casadas, desquitadas - já que essa posição aparece como fundamental na definição desse projeto. É como se antes de se casar ou após descasar o projeto familiar assumisse menor importância em relação ao projeto de vida como um todo. A ênfase presente nos relatos de todas as entrevistadas na relação conjugal, definida pelo parceiro e pelos filhos, como parâmetro do projeto familiar, revela que as decisões tomadas em relação a ter ou não ter um filho se referem à possibilidade de concretização do projeto familiar.

$\mathrm{Na}$ análise dos projetos de vida explicitados nas justificativas dadas ao aborto as diferenças mostram que para as solteiras a ênfase maior se dá em relação ao projeto de vida, enquanto que as casadas reafirmam o projeto familiar, e as desquitadas retomam seus projetos de vida.

A participação do parceiro no processo de decisão pelo aborto também mostra variações. No caso de mulheres solteiras, as variações podem ser atribuídas ao tipo de relação vivida por ocasião da gravidez que resultou em aborto. No caso das solteiras tomadas como contraponto o mesmo se verifica. É recorrente, entretanto, nos relatos, a percepção do aborto como sendo uma decisão da mulher, já que o parceiro se mostra solidário a uma decisão tomada por ela ou então se vê excluído desse processo por determinação da própria mulher, que passa a assumir para si o controle da reprodução.

Para as mulheres casadas, o maior ou menor envolvimento do marido parece estar relacionado à fase vivida no casamento, constatando-se mais uma vez que para as mulheres entrevistadas a decisão em caso de aborto pertence à mulher.

No caso de mulheres desquitadas, as variações de comportamento por parte dos parceiros podem ser atribuídas ao tipo de relação vivida por ocasião da gravidez, como no caso das mulheres solteiras ou podem ser remetidas à fase vivida no casamento, como no caso das mulheres casadas, verificando-se também aqui que o parceiro ou é solidário à decisão tomada ou se vê excluído desse processo, reafirmando a percepção do aborto como sendo uma decisão pertencente à mulher.

A diferença mais radical nos depoimentos se dá em termos das condições em que o aborto é realizado. As mulheres pertencentes à "classe média" parecem ter relativa facilidade no acesso a clínicas e hospitais. Apesar da margem razoável de segurança quanto aos riscos em termos de saúde, o atendimento recebido é percebido como hostil, sendo enfatizados a frieza e o distanciamento dispensados pelo médico no tratamento dos casos de aborto. Fato que pode ser atribuído à clandestinidade da sua prática, que parece isentar o médico da responsabilidade em relação à saúde da mulher que aborta, uma vez que qualquer denúncia em caso de maus tratos ou sequelas do aborto por parte da mulher que o praticou implica na sua própria punição, já que ambos, mulher e médico, são cúmplices de uma ação proibida legalmente.

Ao contrário das mulheres pertencentes à "classe média", as mulheres entrevistadas tomadas como contraponto não têm a possibilidade do acesso às clínicas e hospitais, realizando o aborto através do uso de injeção, chás abortivos, ou então recorrendo a "uma dessas mulheres". Nestes casos é sempre prevista a possibilidade dos 
riscos em termos de saúde acarretados pelo aborto e elas em geral necessitam do atendimento médico posterior.

Nesse sentido os dados obtidos nesta pesquisa confirmam as informações mencionadas nas pesquisas médicas, citadas na primeira parte, quando se refere à alta participação dos médicos nos casos de aborto (Milanesi 1970) e ainda quando revelam as consequências pós-abortivas decorrentes da precariedade das condições em que o aborto é realizado por mulheres que não têm acesso a clínicas e hospitais (Falconi 1968).

Além disso, na pesquisa de Milanesi, a autora sugere que não eram as mulheres que tinham muitos filhos as que recorriam ao aborto. Os dados obtidos pela autora revelam também que o controle de fertilidade foi "consideravelmente" praticado durante a vida reprodutiva da mulher, sendo que as gestações que terminaram em aborto não poderiam ser atribuídas a falha do anticoncepcional. Outro dado obtido se refere à alta percentagem de mulheres católicas que praticam aborto. Estas observações são confirmadas nos seus contornos por esta pesquisa.

Por outro lado, ao contrário do que encontrou Falconi, as entrevistadas na minha pesquisa não demonstraram "temor à lei ou vergonha diante do ato cometido" apesar de revelarem ser esta uma experiência dolorosa, enfatizando a solidão como um sentimento inerente a essa vivência. Também não se confirmou a sugestão de Martino de que o aborto seja utilizado pelas mulheres da "classe baixa" como método anticoncepcional.

Para todas as mulheres entrevistadas o aborto aparecia como um último recurso diante de uma gravidez indesejada. Dado que sugere que ao invés de se propor "maior rigor na lei a fim de evitar esse mal" como indica Falconi, ou então como pretende Milanesi "maior divulgação e exigência do cumprimento da ética médica" como uma das medidas a serem tomadas na "repressão de tão grave problema", parece necessário como defendem os grupos feministas, maior acesso às informações e aos recursos disponíveis para controlar a reprodução. Se essa experiência foi percebida como difícil e dolorosa por todas as mulheres que entrevistei, isso se prendia em grande parte às condições em que o aborto era necessariamente praticado, o que sugere que além de melhor informação em geral a respeito dos métodos anticoncepcionais, o acesso a esse "último recurso" deveria ser respeitado e garantido que sua realização se desse em melhores condições. (Digiovani 1983: 174-181).

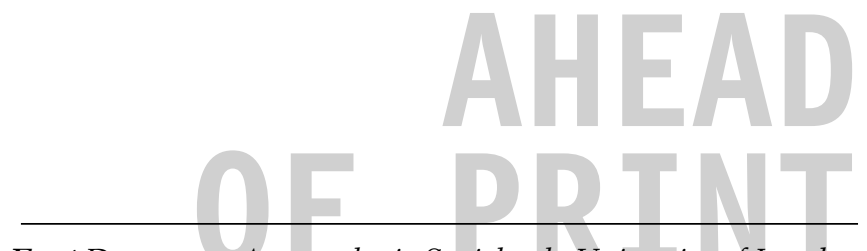

Peter Fry é Doutor em Antropologia Social pela University of London e Professor Emérito da Universidade Federal do Rio de Janeiro (UFRJ). 


\section{REFERÊNCIAS BIBLIOGRÁFICAS}

CORRÊA, Mariza. 1975. Os atos e os autos: representações jurídicas de papéis sexuais. Dissertação de Mestrado (Antropologia Social). Campinas: Universidade Estadual de Campinas.

. 1981. Os Crimes da Paixão. São Paulo: Brasiliense (Coleção Tudo é História).

. 1983. Morte em Família. Rio de Janeiro: Graal.

DIGIOVANI, Rosângela. 1983. Projetos de vida: um estudo das representações femininas do aborto. Dissertação de Mestrado (Antropologia Social). Campinas: Universidade Estadual de Campinas. Disponível em: <http://www. bibliotecadigital.unicamp.br/document/?code $=000047149>$.

FALCONI, Flávio R. M. 1968. Incidencia de aborto provocado em el amparo maternal durante el ano de 1967. Dissertação de Mestrado, Faculdade de Higiene e Saúde Pública, Universidade de São Paulo.

GUIMARÃES, Ercy Parreira. 1978. A imagem refletida: contribuição ao estudo dos papéis da mulher casada. Dissertação de Mestrado (Antropologia Social). Campinas: Universidade Estadual de Campinas.

LOBERT, Rosemary. 1979. A Palavra Mágica Dzi: Uma Resposta Difícil de se Perguntar - a vida cotidiana de um grupo teatral. Dissertação (Mestrado em Antropologia Social). Campinas: Universidade Estadual de Campinas.

. 2010. A palavra mágica: A vida cotidiana do Dzi Croquettes. Campinas: Ed. UNICAMP.

MAZZARIOL, Regina Maria. 1977. "Mal Necessário": Ensaio Sobre o Confinamento da Prostituição na Cidade de Campinas. Dissertação (Mestrado em Antropologia Social). Campinas: Universidade Estadual de Campinas.

MILANESI, Maria Lucila. 1970. O aborto provocado. São Paulo: Edusp.

PERLONGHER, Néstor. 1986. O Negócio do Michê: prostituição viril em São Paulo. Dissertação (Mestrado em Antropologia Social). Campinas: Universidade Estadual de Campinas.

. 1987. O negócio do michê: prostituição viril em São Paulo. 2 ed. São Paulo: Brasiliense.

STOLCKE, Verena. 1986. Cafeicultura: Homens, Mulheres e Capital (1850-1980). São Paulo: Brasiliense.

TURNER, Victor. 1975. Dramas, Fields and Metaphors. Cornell University Press.

VELHO, Gilberto. 1981. Individualismo e cultura. Notas para uma antropologia da sociedade contemporânea. Rio de Janeiro: Zahar.

Recebido em: 22/06/2015 